\title{
Studies on Enhanced Oxidation of Estrone and Its Voltammetric Determination at Carbon Paste Electrode in the Presence of Cetyltrimethylammonium Bromide
}

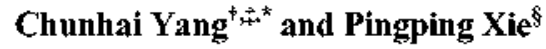 \\ ${ }^{4}$ Key Laboratory of Biological Resontces Protection and Utilization of Hubei Province, Enshi 445000, P.R. China \\ 'Department of Chemistry, Hubei Institute for Nationalities, Enshi 4450\%), P.R. China. "E-mail: Yangchunhailo1@163.com \\ $\$$ PetroChina DaLian Labe Oil R\&D Institute, Dalian 116031, P.R. China
}

Received Angust 31,2006

\begin{abstract}
The electrochemical behaviors of estrone in the presence of various surfactants were examined with great details. It is found that a cationic surfactant, cetyltrimethylammonium bromide (CT $\mathrm{B}$ ), obviously facilitates the electro-oxidation of estrone at carbon paste electrode (CPE) from the significant peak current enhancement and the negative shift of peak potential. $\Lambda$ dditionally, chronocoulometry and electrochemical impedance spectroscopy (EIS) were also used for further investigation of the electrode process of estrone, indicating that low concentration of $\mathrm{CT} \Lambda \mathrm{B}$ exhibits excellent enhancement effects on the electrochemical oxidation of estrone, greatly enhances the diffusion coefficient and the electron transfer rate. Based on this, an electrochemical method was proposed for the determination of estrone. The oxidation peak current is proportional to the concentration of estrone in the ranges over $9.0 \times 10^{-8}-8.0 \times 10^{-6} \mathrm{~mol} / \mathrm{L}$, and a low detection limit of $4.0 \times 10^{-8} \mathrm{~mol} / \mathrm{L}$ was obtained for $180 \mathrm{~s}$ accumulation at open circuit $(\mathrm{S} / \mathrm{N}=3)$. Finally, this proposed method was demonstrated using estrone tablets with good satisfaction.
\end{abstract}

Key Words : Surfactant, Estrone, Determination, Carbon paste electrode, Electroanalysis

\section{Introduction}

Estrone is one kind of essential substrates of human beings, and plays very important roles in women's fertility. Its concentration and the change of concentration are closely related to human's health since both the lack and overmuch of estrone will lead to diseases.' Therefore, developing sensitive, rapid and simple method for the determination of estrone is very important.

So far, various methods such as gas chromatography-mass spectrum (GC-MS), ${ }^{2.3}$ high performance liquid chromatography (HPLC) ${ }^{4,5}$ and immunoassay ${ }^{6}$ have been reported for the determination of estrone. Although these methods possess high sensitivity and excellent selectivity, they have many intrinsic drawbacks: time-consuming, needing complicated and expensive instruments, and high cost.

Electrochemical method is drawing increasing attention due to its many advantages: high sensitivity, good sensitivity, rapid response, low cost and simplicity. To date, a great number of electrochemical methods were developed for the determination of estrogens. ${ }^{7-13}$ For example, a sensitive electrochemical method for the determination of estrogens based on a Nafion-modified electrode and enhancement effect of surfactant was reported..$^{10}$ The detection limit is as low as $10^{-9} \mathrm{~mol} / \mathrm{L}$. Otherwise, a voltammetric method utilizing the catalytic effect of carbon nanotubes (CNTs) was also reported for the determination of estradiol with detection limit of $10^{-8} \mathrm{~mol} / \mathrm{L}$." $\mathrm{Nano}-\mathrm{Al}_{2} \mathrm{O}_{3}$ film-modified glassy carbon electrode was fabricated for the determination of estradiol and the lowest detectable concentration is $8 \times 10^{-8} \mathrm{~mol} / \mathrm{L}^{12}$ Additionally, an electrochemical method using carbamylcholine $(\mathrm{CCh})$ modified paraffin-impregnated graphite electrode (CCh/WGE) was reported for the determination of estradiol, estrone and estriol. ${ }^{13}$ However, to the best of our knowledge, electrochemical determination of estrone using a carbon paste electrode and in the presence of CTAB has not been reported.

CTAB, a cationic surfactant with a hydrophilic head on one side and a long hydrophobic head on the other side, had been widely used in electrochemistry and electroanalytical chemistry field for different purposes. ${ }^{1+17}$ It is well known that surfactants not only endow the electrode/solution interface with different electrical properties, but also adsorb at electrode surface or aggregate into supermolecular structures to change electrochemical process..$^{18-21}$

The main objective of the current work is to propose an easy, quick and sensitive electrochemical procedure for the determination of estrone utilizing the special electrochemical characterization of $\mathrm{CTAB}$. It is found that the cation surfactant CTAB had a distinct enhancement effect on the oxidation of estrone at carbon paste electrode. Additionally, the reaction mechanism for the oxidation of estrone was explored by chronocoulometry, and then experimental conditions for the determination of estrone were optimized. Finally, this new sensitive method was applied to the determination of estrone in the compound estrone tablets and the results are satisfying.

\section{Experimental}

Reagents. $2.0 \times 10^{-3} \mathrm{~mol} / \mathrm{L}$ estrone stock solution was prepared by dissolving estrone (Sigma chemical reagent $\mathrm{Co}$., USA) in ethanol. Graphite powder was obtained from Shanghai Reagent Corporation, China. CTAB (purchased 
from Shanghai Reagent Corporation, China) was dissolved in re-distilled water to form $1.0 \times 10^{-2} \mathrm{~mol} / \mathrm{L}$ homogeneous solutions. All chemicals were of analytical grade quality and were used without further purification. The experimental results were obtained at room temperature.

Apparatus. Electrochemical measurements were performed on a $\mathrm{CHI} 660$ electrochemical analyzer (Chenhua Co., Shanghai, China). The electrode system contains a carbon paste working electrode ( $2.7 \mathrm{~mm}$ in diameter), a $\mathrm{Pt}$ wire counter electrode and a saturated calomel reference electrode (SCE). The electrochemical impedance spectroscopy (EIS) was carried out with the EG\&G Model 273 electrochemical workstation and EG\&G Model 5210 lock-in amplifier (Princeton Applied Research, PAR, USA) powered by Echem Software.

Preparation of carbon paste electrode. The carbon paste electrode was prepared by mixing $100.0 \mathrm{mg}$ graphite power (320 mesh, Shanghai Reagent Corporation, China) and 25.0 $\mu \mathrm{L}$ paraffin oil in a small mortar to form a homogeneous carbon paste mixture. Then, the mixture was pressed by hand into the end cavity of a homemade polytetrafluoroethylene (PTFE) cylindrical electrode body. Finally, the electrode surface was polished manually on a piece of weighing paper.

Analytical procedure. Unless otherwise indicated, 0.1 $\mathrm{mol} / \mathrm{L}$ phosphate buffer solution $(\mathrm{PB}, \mathrm{pH} 8.0)$ was used as the supporting electrolyte in a conventional electrochemical cell. At the beginning of experiment, The carbon paste electrode was scanned by successive cyclic voltammetric sweeps between $0.00 \mathrm{~V}$ and $1.00 \mathrm{~V}$ at $100 \mathrm{mV} / \mathrm{s}$ to get a steady cyclic voltammograms, and then known volume of estrone stock solution and $1.0 \times 10^{-4} \mathrm{~mol} / \mathrm{L} \mathrm{CTAB}$ were placed into the cell to make up $5 \mathrm{~mL}$ mixture solution. After accumulating at open circuit for 180 s with stirring the solution and keeping quiescent for 10 s, the linear sweep voltammograms were recorded in the potential range $0.0-1.0$ $\mathrm{V}$ with scan rate of $200 \mathrm{mV} / \mathrm{s}$. The oxidation peak current was measured at $0.52 \mathrm{~V}$.

\section{Results and Discussion}

Electrochemical impedance spectroscopy of estrone. The property of electrode interfaces can be investigated by electrochemical impedance spectroscopy (EIS). ${ }^{22-25}$ In EIS, the semicircle diameter equals the electron transfer resistance. Figure I shows the complex plane diagram (Nyquist plot, $Z^{\prime \prime}$ versus $Z^{\prime}$ ) of estrone at carbon paste electrode in the absence (Fig. 1a) and presence of CTAB (Fig. 1b). From the comparison, it is very clear that the impedance responses of estrone show great difference after addition of CTAB. In the absence of CTAB, the impedance spectra include a semicircle with a large diameter. However, after addition of $\mathrm{CTAB}$, the diameter of semicircle diminishes markedly. It is clear that the charge transfer resistance of electro-oxidation of estrone decreases greatly, and the charge transfer rate speeds up by $\mathrm{CTAB}$, suggesting that $\mathrm{CTAB}$ facilitates the electron transfer between estrone and electrode.

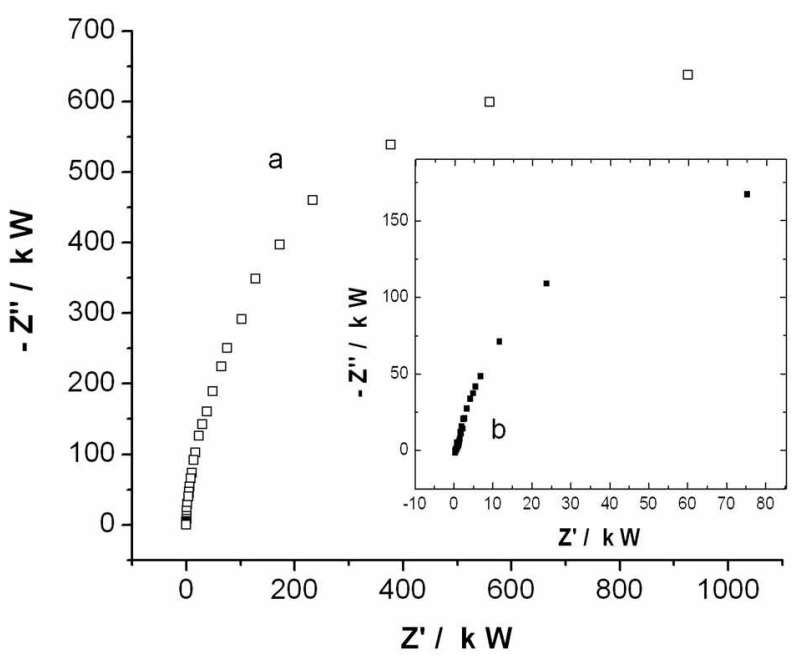

Figure 1. Nyquist diagram (Z"vs. Z') for cstronc at carbon paste electrode in the absence (a) and presence (b) of CTAB. estrone: 2.0 $\times 10^{-5} \mathrm{~mol} / \mathrm{L}$; CTAB: $1.0 \times 10^{-4} \mathrm{~mol} / \mathrm{L}$. Frequency range used, 100 $\mathrm{kHz}$ to $0.1 \mathrm{~Hz}$ with signal anplitude of $5 \mathrm{mV}$ nns at five steps per decade.

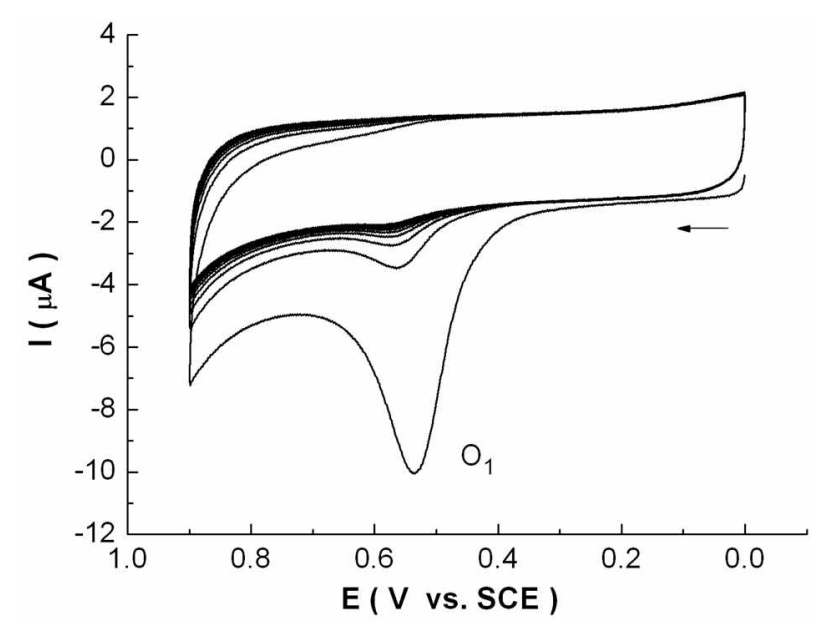

Figure 2. Successive cyclic voltammograms of $8.0 \times 10^{-6} \mathrm{~mol} / \mathrm{L}$ estrone in $0.1 \mathrm{~mol} / \mathrm{L}$ phosphate buffer solution $(\mathrm{pH} 8.0)$. Scan rate: $100 \mathrm{mV} / \mathrm{s} ; \mathrm{CTAB}: 1.0 \times 10^{-4} \mathrm{~mol} / \mathrm{L} ; \Lambda$ cculnulation time: $180 \mathrm{~s} ;$ rest time: $10 \mathrm{~s}$.

The voltammetric behaviors of estrone. Figure 2 shows the successive cyclic voltammograms of $1.0 \times 10^{5} \mathrm{~mol} / \mathrm{L}$ estrone in $5 \mathrm{~mL}$ phosphate buffer solution $(\mathrm{pH} 8.0)$ at $\mathrm{CPE}$ in the presence of $1.0 \times 10^{+} \mathrm{mol} / \mathrm{L}$ CTAB. A well-defined oxidation peak $(\mathrm{O} 1)$ is observed at $0.53 \mathrm{~V}$ at the first anodic sweep from 0.00 to $1.10 \mathrm{~V}$. On the reversal scan, no corresponding reduction peak appears. However, during following successive cyclic sweeps, the peak current of $\mathrm{OI}$ decreases greatly and finally disappears. It is resulted from the fact that the electrode surface is blocked by the adsorption of oxidation products, which reducing the effective reaction sites at CPE surface. This is true for the case without CTAB expect that the blocking effect is apparently reduced in the presence of CTAB. Similar results have been reported by us recently. ${ }^{26}$

The electrochemical behaviors of estrone at $\mathrm{CPE}$ in $\mathrm{pH} 8.0$ 


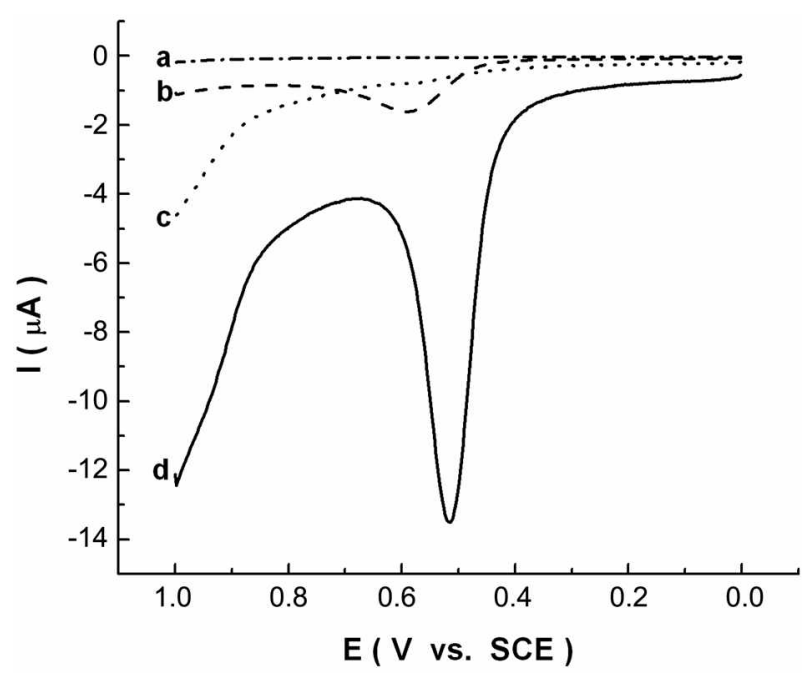

Figure 3. Lincar sweep voltammograuns in $\mathrm{pH} 8.0$ phosphate buffer at carbon paste electrode: a) in the absence of estrone and (TAB; b) in the presence of estrone; $c$ ) in the presence of CTAB; d) in the presence of estrone and CTAB. Scan rate: $200 \mathrm{mv} / \mathrm{s}$; Accuinulation time: $180 \mathrm{~s}$; rest time: $10 \mathrm{~s}$; cstronc: $2.0 \times 10^{-5} \mathrm{~mol} / \mathrm{L}$; CTAB: $1.0 \times 10^{-4} \mathrm{~mol} / \mathrm{L}$.

phosphate buffer were investigated by LSV. Voltammetric responses of estrone are shown in Figure 3. It can be seen that no voltammetric signal appears in the blank buffer solution (curve a) and in the solution only containing CTAB (curve c). However, estrone exhibits a weak oxidation peak at $0.59 \mathrm{~V}$ (curve b) in the absence of CTAB. After the addition of $1.0 \times 10^{-4} \mathrm{~mol} / \mathrm{L} \mathrm{CTAB}$, the oxidation peak current is markedly enhanced and the peak potential shifts negatively to $0.52 \mathrm{~V}$ (curve d). Conclusion can be made that cationic surfactant CTAB has obvious enhancement effect to the oxidation of estrone.

Literatures show that CTAB could be adsorbed to the electrode surface to form surfactants film, ${ }^{27.28}$ which might alter the overpotential of the electrode reactions and influence the rate of electron transfer. In this work, estrone may form transient adduct with $\mathrm{CTAB}$ through the hydrophobic interaction between the hydrophobic tail of CTAB and the hydrophobic moiety of estrone as well as the electrostatic interaction of positively charged CTAB head and the negatively charged phenol group of estrone, which faciliate the adsorption of estrone at CPE surface and makes the oxidation of estrone easier. Therefore, the addition of CTAB increases the adsorption amount of estrone at CPE surface and consequently leads to the enhancement of the oxidation peak current of estrone, compared with those in the absence of CTAB.

Effects of various surfactants on the electro-oxidation of estrone. The effects of various surfactants on the electooxidation of estrone at CPE were explored (depicted in Fig. 4). The electrooxidation response at CPE in the absence of surfactant was shown in curve (a) for comparison. It can be seen that anionic surfactant SDS (curve b), neutral surfactant Triton- $X$ (curve c) and cationic surfactant cetylpyridine bromide (CPB) (curve d), lauryltrimethylammonium bromide

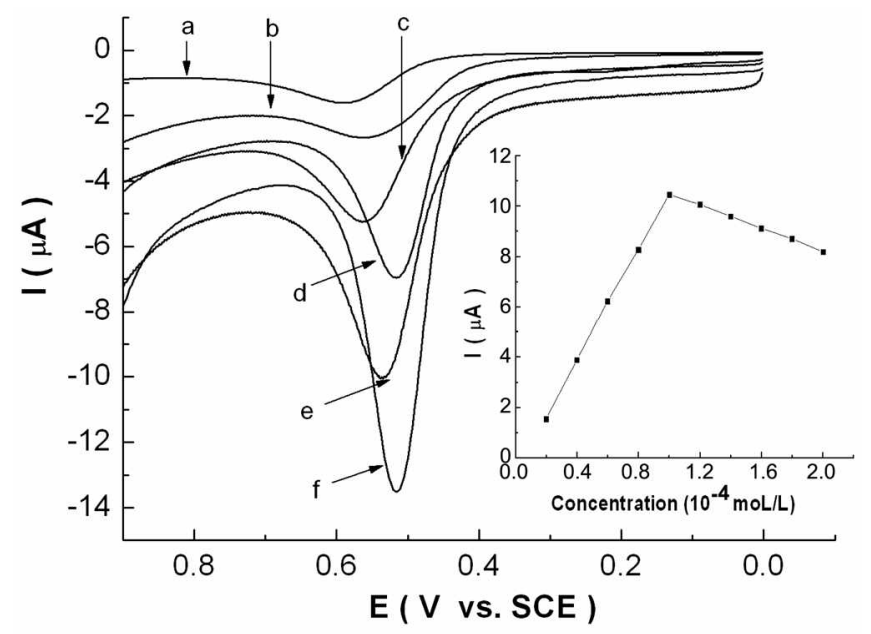

Figure 4. Effects of different surfactants on the oxidation of $2.0 \times$ $10^{-5} \mathrm{~mol} / \mathrm{L}$ cstrone. a. Blank (without surfactants); b. Triton-X-100; c. SDS: d. CPB; e. LTAB; f. CTAB. Surfactant concentration: $1.0 \times$ $10^{-4} \mathrm{~mol} / \mathrm{L}$. Inset: Effects of the amount of CTAB on the oxidation peak curtent. Other conditions are the same as Figure 3.

(LTAB) (curve e), CTAB (curve f) all can improve the oxidation peak current of estrone. However, the degree of enhancement is different under different surfactants due to their different structure, hydrophobic interaction as well as the ion-exchange interactions. Among these, the oxidation peak current of estrone is highest in the existence of $\mathrm{CTAB}$ (curve $f$ ) because of its optimum length of hydrophobic chain and adsorption amount on the electrode surface. ${ }^{1729}$ With either the increase or the decrease of hydrophobic tail length of cationic surfactants, the response of estrone declines. Furthernore, although LTAB and SDS have the same hydrophobic tail length, LTAB produces the much higher response. This can be well explained by the exclusion of negatively charged estrone at $\mathrm{pH} 8.0$ from the electrode surface by the negatively charged SDS film that is adsorbed on the electrode by hydrophobic interactions. Hence, we chose CTAB in this paper.

In addition, the effect of CTAB concentration on the oxidation peak current is shown in as inset plot in Figure 4. The oxidation peak current increases gradually with increase of the concentration of $\mathrm{CTAB}$ and reaches maximum at 100 $\mu \mathrm{M}$, at which $\mathrm{CTAB}$ might form a compact monolayer on $\mathrm{CPE}$ with the hydrophobic tails of CTAB perpendicular to the electrode surface. ${ }^{17.29}$ The increase of estrone oxidation current with increasing CTAB concentration is due to the accumulation of more estrone molecules in the denser $\mathrm{CTAB}$ adsorbed monolayer on CPE. However, the peak current decreases slowly as further increasing the $\mathrm{CTAB}$ concentration. Because the surface of CPE is hydrophobic, $\mathrm{CTAB}$ might adsorb on $\mathrm{CPE}$ via the hydrophobic interaction between the hydrophobic tail of $\mathrm{CTAB}$ and hydrophobic surface of $\mathrm{CPE}$, resulting in the direction of hydrophilic head of $\mathrm{CTAB}$ to solution, i.e. $\mathrm{CTAB}$ forms a compact monolayer with positive charges on $\mathrm{CPE}{ }^{14}$ Thus, the decrease of estrone response by the formation of CTAB micelles should mainly arise from the repress of estrone diffusion in solution 
by CTAB micelles. ${ }^{29}$ So, the oxidation peak current conversely decreases. According to Chidambaram et al, CMC of $\mathrm{CTAB}$ in $0.2 \mathrm{M}$ phosphate buffer is about $5.7 \times 10 \mathrm{M}^{30}$ Thus, the optimal concentration of CTAB is close to its $\mathrm{CMC}$ in $0.1 \mathrm{M}$ phosphate buffer. In this work, the concentration of $\mathrm{CTAB}$ is fixed at $1.0 \times 10^{-4} \mathrm{~mol} / \mathrm{L}$ for higher sensitivity.

Choice of supporting electrolytes. In this work, several kinds of buffer solutions were optimized for the determination of estrone. They include $0.1 \mathrm{~mol} / \mathrm{L}$ phosphate buffer solution (PBS, pH 3.0-9.0), $0.1 \mathrm{~mol} / \mathrm{L}$ sodium acetate-acetic acid buffer solution (NaAc-HAc, $\mathrm{pH} 3.0-9.0$ ), $0.1 \mathrm{~mol} / \mathrm{L}$ sodium citrate-hydrochloric acid (HCl) buffer solution $(\mathrm{pH}$ $1.0-4.0), 0.1 \mathrm{~mol} / \mathrm{L}$ sodium citrate-sodjum hydroxide $(\mathrm{NaOH})$ buffer solution ( $\mathrm{pH} 5.0-7.0), 0.1 \mathrm{~mol} / \mathrm{L}$ borax-hydrochloric acid buffer solution ( $\mathrm{pH} 7.6-9.2), 0.1 \mathrm{~mol} / \mathrm{L}$ borax-sodium hydroxide buffer solution ( $\mathrm{pH} 9.2-12.3$ ). Moreover, different acids and alkalies were investigated too, such as $\mathrm{HCl}(0.1$ $\mathrm{mol} / \mathrm{L}), \mathrm{HAc}(0.1 \mathrm{~mol} / \mathrm{L})$, and $\mathrm{NaOH}(0.1 \mathrm{~mol} / \mathrm{L})$. It is found that higher peak current and better peak shape was obtained in $0.1 \mathrm{~mol} / \mathrm{L}$ phosphate buffer solution. Consequently, 0.1 $\mathrm{mol} / \mathrm{L}$ phosphate buffer solution was chosen as support electrolyte for quantitative analysis of estrone.

The effects of solution $\mathrm{pH}$ played an important role in quantitative detection of trace estrone. Figure 5 depicts the influences of $\mathrm{pH}$ of phosphate buffer on the oxidation peak current and peak potential were researched by LSV. When the $\mathrm{pH}$ increases from 4.0 to 10.0 , the oxidation peak current of estrone changes remarkably, and reaches maximum at $\mathrm{pH}$ 8.0. However, the oxidation peak potential (Ep) shifts negatively, obeying the equation $\mathrm{E}_{\mathrm{p}}=1.1246-0.062 \mathrm{l} \mathrm{pH}(\mathrm{R}$ $=0.9977)$. The slope of $-0.062 \mathrm{mV} / \mathrm{pH}$ suggested that the number of the electrons transferred in the oxidation of estrone is equal with that of protons. Therefore, $0.1 \mathrm{~mol} / \mathrm{L}$ phosphate buffer solution $(\mathrm{pH} 8.0)$ was used as supporting electrolyte for estrone analysis.

Influences of accumulation potential and time. Effect

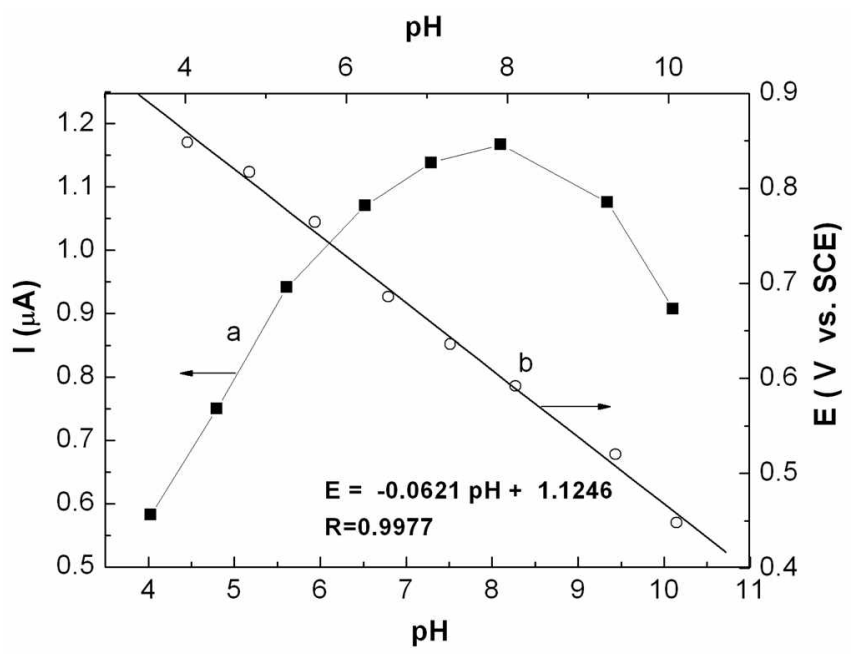

Figure 5. The $\mathrm{pH}$ dependence on $2.0 \times 10^{-5} \mathrm{~mol} / \mathrm{L}$ estrone oxidation peak current (a) and peak potential (b) in the presence of CTAB. Other conditions are the same as in Figure 3.

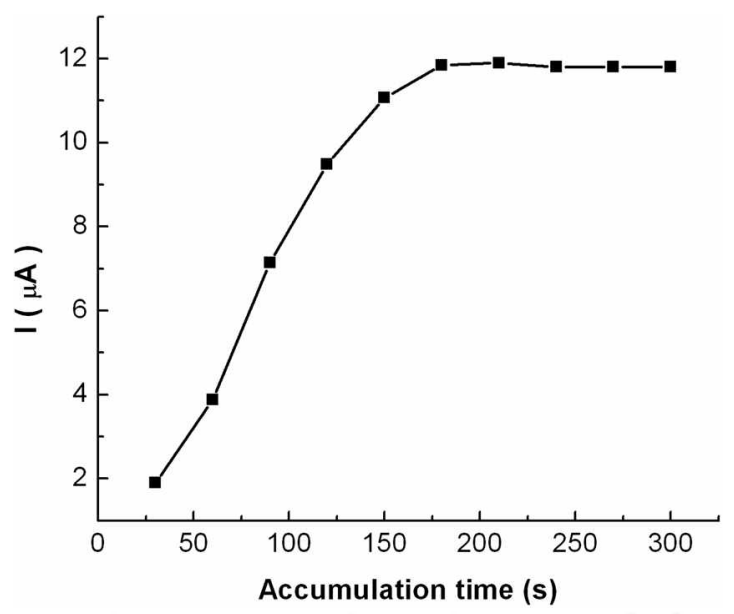

Figure 6. Effects of accurnulation tunc on the oxldation peak current of $2.0 \times 10^{-5} \mathrm{~mol} / \mathrm{L}$ estronc. Other conditions are the same as in Figure 3.

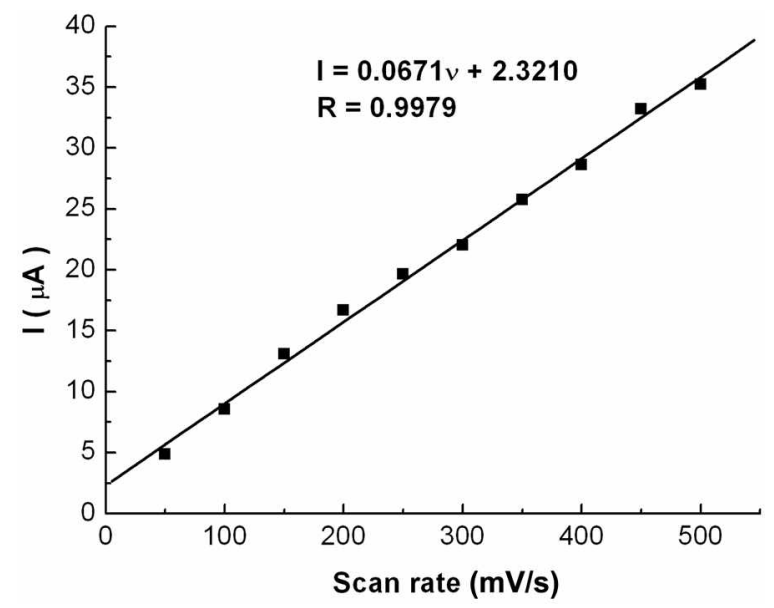

Figure 7. Voltanmograms of $2.0 \times 10^{-5} \mathrm{~mol} / \mathrm{L}$ estrone with different scan rates. Other conditions are the sane as in Figure 3.

of accumulation potential on the oxidation peak current of estrone at CPE was examined. When the accumulation potential shifts from -0.3 to $0.3 \mathrm{~V}$, the oxidation peak current varies slightly, demonstrating that the adsorption of CTAB is independent of the charge on electrode surface. That is to say, the accumulation potential has no obvious influence on the oxidation of estrone.

Influence of accumulation time on the oxidation peak current of estrone at CPE was shown in Figure 6. The oxidation peak current increases linearly with accumulation time in the range of $30-180 \mathrm{~s}$. Afterwards, the peak current tends to be stable with further increasing accumulation time due to the saturated adsorption of estrone on the electrode surface. Therefore, the optimal accumulation time of $180 \mathrm{~s}$ was employed in the experiment.

Scan rate. The effects of scan rate $(v)$ on the oxidation of $2.0 \times 10^{-5} \mathrm{~mol} / \mathrm{L}$ estrone were examined by LSV and the data were list in Figure 7 . The peak current increased linearly with scan rate from 50 to $500 \mathrm{mV} / \mathrm{s}$, and can be expressed as follows: 


$$
\mathrm{I}_{\mathrm{P}}(\mu \mathrm{A})=0.067 \mathrm{v}(\mathrm{mV} / \mathrm{s})+2.3210(\mathrm{R}=0.9979)
$$

Which indicates that the oxidation process of estrone is mainly controlled by adsorption.

Additionally, the relationship between Ep and $v$ was also investigated, described by following equation:

$$
E_{p}=0.0536 \ln v+0.2325(R=0.9974)
$$

As far as totally irreversible electrode process controlled by adsorption step was concemed, the relationship between Ep and $v$ is defined by the following equation ${ }^{31}$ :

$$
\mathrm{E}_{\mathrm{p}}=\mathrm{E}^{o}+\left(\mathrm{RT} / \alpha \mathrm{n}_{\mathrm{a}} \mathrm{F}\right) \ln \left(\mathrm{RTk}^{0} / \alpha \mathrm{n}_{\mathrm{a}} \mathrm{F}\right)+\left(\mathrm{RT} / \alpha \mathrm{n}_{\mathrm{a}} \mathrm{F}\right) \ln u
$$

where $\mathrm{E}^{v}$ is formal potential, $\mathrm{T}$ is temperature, $\alpha$ is the transfer coefficient and $n_{a}$ is the number of the electron transfer in the rate-determining step, $\mathrm{k}^{0}$ is the electrochemical rate constant, $\mathrm{F}$ is the Faraday constant. The slope $\mathrm{RT} / \alpha \mathrm{n}_{\mathrm{l}} \mathrm{F}$ of 0.0536 indicates that the value of $\alpha \mathrm{n}_{\alpha}$ is 0.505 . Based on the assumption of $\alpha$ of 0.5 for the multi-electron transfer process, the value of $n_{\alpha}$ is calculated to be 1 . Combining with the data from the plots of $\mathrm{E}_{\mathrm{p}} \mathrm{rs.} \mathrm{pH}$, it is very clear that the electrochemical oxidation of estrone at $\mathrm{CPE}$ in the presence of $\mathrm{CTAB}$ involves one electron and one proton.

Chronocoulometry. The electrooxidation of estrone at CPE in the absence and presence of CTAB was characterized by chronocoulometry. After the deduction of the background charge, the plot of the charges $(Q)$ against the square root of time $\left(\mathrm{t}^{1 / 2}\right)$ shows a linear relationship (Fig. 8). According to the integrated Cottrell equation ${ }^{32}$, the diffusion coefficient of estrone can be estimated from the slope of the plot of Q $1 s . t^{1 / 2}$.

$$
\mathrm{Q}=2 \mathrm{nFAcD} \mathrm{t}^{1 / 2} \mathrm{t}^{1 / 2} \pi^{-1 / 2}+\mathrm{Q}_{\mathrm{dl}}+\mathrm{Q}_{\mathrm{dds}}
$$

Where $A$ is the area of carbon paste electrode, $c$ is the concentration of estrone, $Q_{d l}$ is the double layer charge, $Q_{\text {adk }}$ is the adsorption charge. Other symbols have their usual

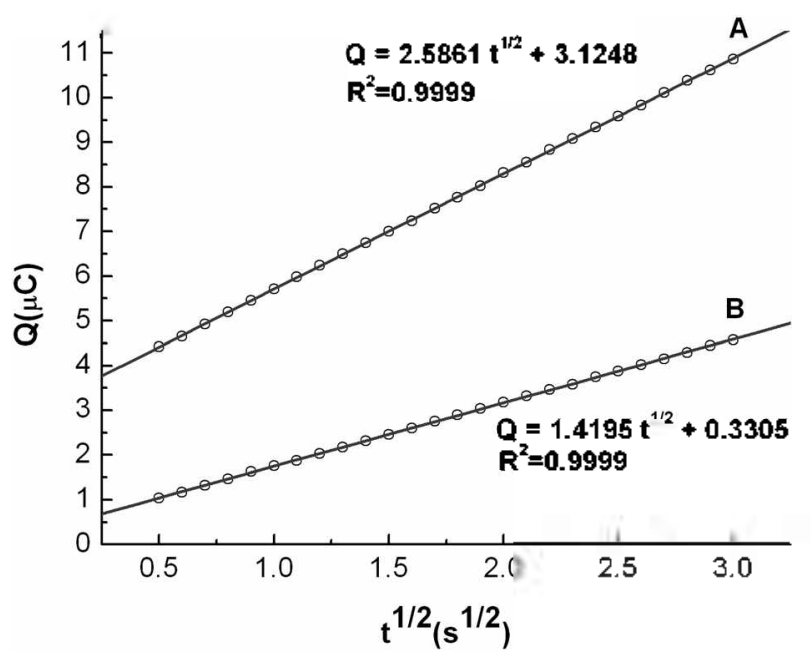

Figure 8. The plot of $\mathrm{Q} v s . \mathrm{t}^{1,2}$ for $2.0 \times 10^{-5} \mathrm{~mol} / \mathrm{L}$ estrone at carbon paste electrode in the presence (a) and absence (b) of $1.0 \times$ $10^{-4} \mathrm{~mol} / \mathrm{L}$ CTAB. Initial potential $0.33 \mathrm{~V}$, final potential $0.53 \mathrm{~V}$ and pulse width 9 . Other conditions are the sane as in Figure 3. significance. In this system the number of transfer electrons involved in the oxidation of estrone is one as calculated above and $\mathrm{A}=0.057 \mathrm{~cm}^{2}, \mathrm{c}=2.0 \times 10^{-5} \mathrm{~mol} / \mathrm{L}$. In the absence and presence of CTAB the value of slope is 1.42 $\mu \mathrm{C} \cdot \mathrm{s}^{-1: 2}$ and $2.59 \mu \mathrm{C} \cdot \mathrm{s}^{-1: 2}$, respectively. It is calculated that D $=1.33 \times 10^{-5} \mathrm{~cm}^{2} \cdot \mathrm{s}^{-1}$ without $\mathrm{CTAB}$, which is increased to $4.40 \times 10^{-5} \mathrm{~cm}^{2} \cdot \mathrm{s}^{-1}$ after the addition of CTAB.

Meanwhile the surface coverage $\Gamma$ of estrone can be evaluated from the following equation:

$$
\mathrm{Q}_{\mathrm{dds}}=\mathrm{nFA \Gamma}
$$

Qds can be obtained by the intercept difference from plot of $Q$ vs. $t^{1 / 2}$ in the absence and presence of estrone when $Q_{d 1}$ is assumed unchanged. In the absence of $\mathrm{CTAB}, \mathrm{Q}_{\mathrm{w}}$ is 0.3305 $\mu \mathrm{C}$, and the value of $\Gamma$ is $6.01 \times 10^{-11} \mathrm{~mol} \cdot \mathrm{cm}^{-2}$. After the addition of $\mathrm{CTAB}, \mathrm{Q}_{\mathrm{dds}}$ increased to $3.1248 \mu \mathrm{C}$, and $\Gamma$ increases to $5.68 \times 10^{-10} \mathrm{~mol} \cdot \mathrm{cm}^{-2}$. Due to the complicated surface properties of CPE, it is impossible to compare the adsorbed amount of estrone to the calculated coverage with the geometrical dimension of estrone. Whereas, the surface coverage of estrone reported here is reasonable because it is close to our previous reports. ${ }^{33}$ It reveals that the adsorption amount of estrone on the electrode surface increased in the presence of CTAB.

Calibration and interferences. Under optimal working conditions described above, the calibration curve of estrone at $\mathrm{CPE}$ in the presence of $\mathrm{CTAB}$ was characterized. In the range of $9.0 \times 10^{-8}-8.0 \times 10^{-6} \mathrm{~mol} / \mathrm{L}$, the oxidation peak current was linear with the concentration of estrone. The linear regression equation can be described as following:

$$
\mathrm{I}_{\mathrm{p}}(\mu \mathrm{A})=0.87764 \mathrm{c}(\mu \mathrm{mol} / \mathrm{L})+0.85262(\mathrm{r}=0.9945)
$$

A detection limit of $4.0 \times 10^{-8} \mathrm{M}$ estrone was obtained with 180 s accumulation time under open circuit. In this work, the used CPE was refreshed after each measurement, and the relative standard deviation (RSD) was $3.2 \%$ for 8 times parallel detection of $2.0 \times 10^{-6} \mathrm{~mol} / \mathrm{L}$ estrone, suggesting excellent reproducibility.

If this electrochemical method would be proposed to detect estrone in real samples, the interferences of some concomitant substances should be estimated. So the effects of some organic compounds on the oxidation of $2.0 \times 10^{-5}$ $\mathrm{mol} / \mathrm{L}$ estrone were evaluated. It is found that 100 -fold concentration of glucose, amylum and dextrin, 50-fold concentration of ascorbic acid (AA), dopamine (DA), uric acid (UA) almost had no interferences on the electrochemical detection of estrone (signal change $<5 \%$ ). In addition, effects of many inorganic ions had also been tested. 100-fold concentration of $\mathrm{Fe}^{3+}, \mathrm{Cu}^{2+}, \mathrm{Zn}^{2+}, \mathrm{Ca}^{2+}, \mathrm{Al}^{3+}, \mathrm{Mg}^{2+}$, $\mathrm{SO}_{4}{ }^{2-}, \mathrm{NO}_{3}^{-}, \mathrm{HCO}_{3}^{-}$did not affect the determination of estrone. However, the influences of hexestrol, estriol and diethylstilbestrol are serious. Because these hormones are hydrophobic and contain hydroxy group, which in benzene ring and may be oxidized, they will cause increase to the oxidation peak current of estrone. What is more, the influences increase as improving their concentration.

Determination of estrone in estrone tablets. The pro- 
Table 1. Detcrmination of estrone in the sample

\begin{tabular}{ccccc}
\hline Sample & $\begin{array}{c}\text { Added } \\
(\mathrm{mol} / \mathrm{L})\end{array}$ & $\begin{array}{c}\text { Expected } \\
(\mathrm{mol} / \mathrm{L})\end{array}$ & $\begin{array}{c}\text { Founded } \\
(\mathrm{mol} / \mathrm{L})\end{array}$ & $\begin{array}{c}\text { Recovery } \\
(\%)\end{array}$ \\
\hline 1 & 0.00 & & $9.85 \times 10^{-8}$ & \\
& $1.0 \times 10^{-7}$ & $1.985 \times 10^{-7}$ & $1.956 \times 10^{-7}$ & 97.1 \\
2 & 0.00 & & & $3.15 \times 10^{-7}$ \\
& $4.0 \times 10^{-7}$ & $7.15 \times 10^{-7}$ & $7.246 \times 10^{-7}$ & 102.4 \\
3 & 0.00 & & & $9.37 \times 10^{-7}$ \\
& $1.0 \times 10^{-6}$ & $1.937 \times 10^{-6}$ & $1.969 \times 10^{-6}$ & 103.2 \\
\hline
\end{tabular}

posed method was applied to determine estrone in estrone tablets. The results are illustrated in Table 1. In our experiments, the concentration of estrone was calculated using standard addition method. The relative standard deviation of each sample for three times parallel detections is less than $4.0 \%$. In addition, the recovered ratio on the basis of this method was investigated and the value is between 97.1 and $103.2 \%$, indicating that determination of estrone using carbon paste electrode in the presence of CTAB is effective and sensitive.

\section{Conclusion}

In this paper, the electrooxidation of estrone at $\mathrm{CPE}$ in $\mathrm{pH}$ 8.0 phosphate buffer was studied. Cationic surfactant CTAB was successfully introduced to enhance the oxidation of estrone. Due to the amphiphilic character of CTAB, the $\mathrm{C}-\mathrm{H}$ chain can easily adsorb on the carbon paste electrode surface, estrone may form transient adduct with CTAB, which can increase the adsorption amount of estrone on the electrode surface, reducing the overvoltage of the electrode reaction and accelerating electron transfer. Finally, a simple, sensitive, rapid and accurate method was successfully applied for the determination of estrone in the compound estrone tables sample.

Acknowledgements. The authors are grateful to the Natural Science Foundation of Department of Education, Hubei Province (D200629004) for financial support.

\section{References}

1. Abrams, L. S.; Skee, D. A.; Natarajan, J.; Wong, F. A.; Lasseter,
K. C. Contraception 2001, 64, 287.

2. Choi, M. H.; Kim, K. R.; Chung, B. C. Antahst 2000, 125, 711 .

3. Hanselman, T. A.; Graetz, D. A.; Wilkie, A. C.; Szabo, N. J.; Diaz, C. S. Journal of Enirommental Quality 2006, 35, 695.

4. Havlikova, L.; Novakova, L.; Matysova, L.; Sicha, J.; Solich, P. Journal of Chromatogrophy $A$ 2006, $1119,216$.

5. Mizuguchi, T.; Sadaka, S.; Ogasawara, C.; Shimada, K. Journal of Ligtia Chromatography \& Related Technologies 2006, 29,903.

6. Jozef, G.; Guy, M.; Fortune, K. Anal. Chim. Acta 1994, 290. 233.

7. Hu, S. S.; He, Q.; Zhao, Z. F. Anal. Chim. Acta 1992, 259, 305.

8. Hu, S. S.; He, Q.; Zhao, Z. F. Analyst 1992, 117, 181 .

9. Hu, S. S.; Guo, M.; Hu, G, Jiang. M. Anal. Lett. 1995, 28, 1993.

10. Hu, S. S.; Wu, K. B.; Yi, H. C.; Cui, D. F. Antal. Chint. Acta 2002. 464. 209.

11. Sun, Y. Y.; Wu, K. B.; Hu, S. S. Microchim. Acta 2003, 142, 49.

12. $\mathrm{He}, \mathrm{Q}$.; Yuan, S.; Chen, C.; Hu, S. S. Materials Science and Engineering C 2003, 23,621.

13. Jin, G; Lin, X. Electrochim. Acta 2005, 50, 3556.

14. Hu, C. G; Hu, S. S. Electrochimica Acta 2004, 49, 405.

15. Wang, F.; Fei, J. J.; Hu, S. S. Colloid Strfoce B 2004, 39, 95.

16. Huang. W. S. Bull. Korean Chem. Soc. 2005, 26, 1560.

17. $\mathrm{Hu}, \mathrm{C} . \mathrm{G}$; Dang, X. P.; Hu, S. S. J. Electroanal. Chem. 2004, 572 , 161.

18. Plavsic, M.; Krznaric, D.; Cosovic, B. Electroanalysis 1994, 6, 469.

19. Hu, S. S.; Yan, Y. Q.; Zhao, Z. F. Anal. Chim. Acta 1991, 248, 103.

20. Monika, S.; Kurt, K.; Georg, R. Anal. Chim, Acta 1997, 350, 319.

21. Monika, S.; Kur1, K.; Georg, R.; Christian, N. Talanta 1996, 43, 1915.

22. Roto, R.; Villemure, G J. Electroanat. Chem. 2002,527, 123.

23. Gervasi, C. A.; Vallejo, A. E. Electrochin. Acta 2002, 47, 2259.

24. Kim, J. M.; Palwardhan, A.; Bolv, A.; Thompson, D. H. Biochim. Biophys, Acta 2003, 1617, 10.

25. Vázquez, M. I.; Benavente, J. J. Membr. Sci. 2003, 219, 59.

26. Hu, C. G.; Yang, C. H.; Hu, S. S. Electrochemistny Commtnications 2007, 9, 128.

27. Connors, T. F.; Rusling, J. F.; Owlia, A. Anal Chent 1985, 57 , 170 .

28. Kamau, G. N.; Leipert, T.; Shulkla, S.; Rusling, J. F. J. Electroand. Chen. 1987, 233, 173.

29. Yuan, S.; Hu, C. G. Hu, S. S. Electrochimica Acta 2006, 51, 5274 .

30. Chidambaram, N.; Burgess, D. J. Colloids AND Surfaces APhysicochemical AND Engineering Aspects 2001, 181,271.

31. Laviron, E. J. Electroanal. Chem. 1974, 52, 355 .

32. Bard, A. J.; Faulkner, L. R. Electrochemical Methods: Futfdimentals and Applications; Wiley: New York, 2001; p 603.

33. Xie, P. P.; Chen, X. X.; Wang, F.; Hu, S. S. Colloids and Strraces B: Biointerfaces 2006, 48, 17 . 